Engineering Plasticity 


\section{Engineering Plasticity}

Theory and Application to Metal Forming Processes

R. A. C. Slater

Department of Mechanical Engineering

The City University, London

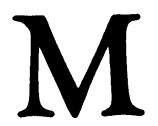


(C) R. A. C. Slater 1977

Softcover reprint of the hardcover 1st edition 1977 978-0-333-15709-1

All rights reserved. No part of this publication may be reproduced or transmitted, in any form or by any means, without permission

First published 1977 by

THE MACMILLAN PRESS LTD

London and Basingstoke Associated companies in New York Dublin

Melbourne Johannesburg and Madras

ISBN 978-1-349-02162-8 ISBN 978-1-349-02160-4 (eBook)

DOI 10.1007/978-1-349-02160-4

Photosetting by Thomson Press (India) Limited, New Delhi 


\section{Contents}

Preface viii

1. Introduction 1

1.1 Definition and Scope of the Subject 1

1.2 Nature of Engineering Plasticity 2

1.3 A Brief Historical Account 3

1.4 Classification of Metal Forming Processes 5

1.5 Forming Limits 7

2. Stress Analysis 11

2.1 Specification of Stress at a Point 11

2.2 Differential Equations of Equilibrium in the Neighbour$\begin{array}{ll}\text { hood of a Point } & 16\end{array}$

2.3 Three-Dimensional Stress Analysis 20

3. Strain Analysis $\quad 37$

3.1 Infinitesimal Deformation $\quad 37$

3.2 Finite Deformation 51

4. Yield Criteria for Ductile Metals 67

4.1 General Considerations $\quad 67$

4.2 Von Mises Yield Criterion 69

4.3 Tresca Yield Criterion $\quad 70$

4.4 Yield Surface for an Isotropic Perfectly Plastic Material 71

4.5 Haigh-Westergaard Stress Space Representation of Yield Criteria $\quad 73$

4.6 Experimental Verification of Yield Criteria 79

4.7 Subsequent Yield Surfaces for an Isotropic StrainHardening Material $\quad 84$

4.8 A Yield Criterion for an Anisotropic Material 86 
5. Stress-Strain Relations

5.1 Elastic Stress-Strain Relations 91

5.2 Elastic Strain Energy Functions 93

5.3 Plastic Stress-Strain Relations 95

5.4 Stress-Strain-Rate Equations 100

5.5 Plastic Work and Strain-Hardening Hypotheses 100

5.6 Experimental Verification of the Prandtl-Reuss Equations

5.7 Derivation of the Generalised Plastic Stress-Strain Relations 105

5.8 The Principle of Maximum Work Dissipation 115

6. Phenomenological Nature of Engineering Metals 119

6.1 Changes in Density and Shape 119

6.2 Quasi-Static Uniaxial Tensile Test 120

6.3 Quasi-Static Compression Tests 134

6.4 Effect of Temperature and Strain-Rate 141

$\begin{array}{ll}\text { 6.5 Anisotropy and Aelotropy } & 152\end{array}$

6.6 Bauschinger Effect 157

6.7 Plastic Instability 159

6.8 Homogeneous Deformation 168

7. Plane Strain Plastic Deformation 175

7.1 Basic Concepts and Assumptions 175

7.2 Fundamental Equations for Plane Plastic Flow 176

7.3 Plane Strain Slip Line Field Theory 182

7.4 Some Applications of the Slip Line Field Theory 209

7.5 Estimation of Plane Strain Forming Parameters by the Stress Evaluation Approach 236

8. Plastic Strain with Axial Symmetry 263

8.1 Fundamental Equations for Plastic Strain with Axial Symmetry

8.2 Approximate Solution for the Quasi-Static Axisymmetric Upsetting of a Circular Cylinder 266

8.3 Fast Homogeneous Compression of a Circular Cylinder 271

8.4 Bar and Wire Drawing Through a Conical Die 274

8.5 Extrusion Through a Conical Die 280

8.6 Optimum Die Angles 291

8.7 Hydrostatic Extrusion 292

8.8 Drawing and Sinking of a Thin-Walled Tube Through a Conical Die 
9.1 Basic Concepts and Assumptions 310

9.2 Equations of Plane Stress with von Mises Yield Criterion 312

9.3 Simple Stress States 316

9.4 Equilibrium of a Thin Plate with a Circular Hole Subjected to Uniform Pressure

9.5 Plastic Bending of a Thin Circular Plate 321

9.6 Deep Drawing of a Circular Sheet Metal Blank 328

\section{Extremum Principles for a Rigid-Perfectly Plastic Material 348}

10.1 General Considerations 348

10.2 Basic Energy Equation or Virtual Work Equation 349

10.3 Surfaces of Stress and Velocity Discontinuity 351

10.4 Uniqueness Theorem for a Rigid-Perfectly Plastic Body 354

10.5 The Lower Bound Theorem 356

10.6 The Upper Bound Theorem 358

10.7 Some Applications of the Upper Bound Theorem to Plane Strain Deformation (Johnson Upper Bound Estimates)

10.8 Upper Bound Estimates for Anisotropic Metals

10.9 Lines of Thermal Discontinuity or 'Heat Lines' and Temperature Jumps During a Fast Metal Forming Process

10.10 Plastic Bending of a Notched Bar-the Plastic Hinge 390

10.11 Upper Bound Estimates Involving Unit Deforming Regions (Kudo Upper Bound Estimates)

10.12 Upper Bound Estimates for Axisymmetric Deformation (Kobayashi Upper Bound Estimates)

10.13 Upper Bound Estimates for the Plastic Bending of Transversely Loaded Thin Plates

Appendices

1 The Rule of Sarrus for the expansion of third-order determinants

2 The characteristics of partial differential equations 


\section{Preface}

Except for castings, which are formed from the liquid state, all metal products are subjected to at least one metal forming process during their manufacture. In such processes the desired change in shape of the metal is effected without metal removal. The deformation is permanent and involves predominantly large plastic strains. The elastic strains are then of lesser significance.

With the current rapid technological progress, the theory of plasticity has been brought forcibly into the forefront of engineering application and design. The facts of economic life have made the efficient utilisation of material, labour and time and a more efficient approach to design a necessity even for the less sophisticated industrial applications. Today there is, therefore, a greater need for all mechanical and manufacturing engineers to be familiar with the fundamentals of metal forming analysis, not only to be more numerate and hence reduce the extent of empirical approach to problems, but also to close the gap which exists at the interface between design and manufacture.

Although the theory of plasticity has advanced considerably in the last few decades, rigorous solutions to all metal forming problems are still not available. However, simplified versions of practical processes assuming idealised materials and boundary conditions give valuable insight into the effects of various parameters such as the extent of deformation, tool profile, speed and lubrication on the force, energy and power requirements. The resulting temperature changes, forming limits and the final properties of the manufactured products can be assessed.

This particular text is based on lectures relating to the theory of plasticity and its specific application to metal forming processes which have been given during my university career at one time or another. They have been addressed to advanced undergraduates commencing in the second year of their studies and also to postgraduate students in mechanical engineering and manufacturing engineering.

My principal aim in producing this text is, therefore, to bring within the scope of advanced undergraduates and those studying for higher degrees 
in mechanical engineering and manufacturing engineering, at universities and polytechnics, a compilation of information and some analytical methods in the subject of ENGINEERING PLASTICITY and its specific application to metal forming processes. In addition, it is hoped that the account presented of the principles of metal forming theory and application will be of benefit to all practising engineers and metallurgists who are directly concerned with improving design and efficiency in the manufacturing industry.

In the preparation of this book it was obviously impossible to include all aspects of the metal forming processes. Rather than attempt to cover the whole field in a cursory manner I have preferred to consider a wide range of selected topics and present the treatment of these as complete and factual as possible. All the theory of plasticity necessary for this purpose is included.

The textbook is not intended to be a mathematical treatise but, equally, it contains little descriptive detail of the many complexities of modern metal forming processes. For these reasons a mainly technological approach to the subject is adopted and it is hoped that this is reflected in the choice of title.

Metal forming, like all engineering activities, is essentially interdisciplinary. It is therefore necessary, for example, for readers to be familiar with the relevant metallurgical aspects. The various implications of physical metallurgy or materials science which affect the applications of plasticity should be borne in mind. However, it has proved impossible to include such information in the present text but excellent textbooks are now available on this subject.

It is often assumed that readers who have an interest in plasticity theory and its various applications are familiar with the basic concepts of stress and strain analyses. Nevertheless, it is my experience that this is not always the case. Chapter 2 (Stress Analysis) and chapter 3 (Strain Analysis) are consequently presented in some detail so as to avoid the need to refer to other texts and also to refresh the memory of those readers who have, indeed, previously studied these concepts.

Stress and strain as well as being vector quantities are also second-order tensors. Although there is no intention to be mainly concerned with tensors and their properties as such, it is important that readers are at least familiar with the subscript notation known as 'tensor' notation. This notation is not only a convenient and shorthand way of stating mathematical expressions, but is also extremely useful in derivations and in the proof of some theorems. Many research papers employ this type of notation. It is assumed that the reader has acquired sufficient knowledge to interpret this notation without much difficulty.

For the development of a plasticity theory, the stress states at which plastic flow or yielding will occur, and the flow rules or relations between stress and strain when plastic flow does occur, are necessary. Chapter 4 discusses yield criteria and their experimental verification but is restricted 
to ductile metals which are of greatest importance in metal forming. In chapter 5, the stress-strain relations are developed and discussed.

Having established the fundamental principles of plasticity theory, but before attempting to apply these, chapter 6 is introduced. This is concerned with the macroscopic behaviour of real engineering metals and is thus intended to focus the attention on the complex behaviour of metals and hence highlight the various limitations which are imposed when applying any theory.

Chapters 7 to 9 inclusive endeavour to employ the preceding theory in solving a number of metal forming problems which are likely to be of special interest to the student and practising manufacturing engineer. These are classified in terms of plane strain deformation, plastic strain with axial symmetry and plane stress or pseudo-plane-stress problems.

Chapter 10 presents and discusses the so-called 'extremum' principles for an ideal rigid perfectly plastic material leading to the formulation of the lower and upper bound theorems. This latter theorem is particularly useful in engineering applications because it can be employed to furnish an acceptable overestimate of the important forming parameters.

I am conscious of the fact that the material presented in this text could be adversely criticised. For example, limited reference is made to inertia effects and the propagation of elastic and plastic waves upon the analyses of the processes. Consequently, the treatment is essentially through a quasi-static approach. No serious attempt is made to deal with the tribological aspects of metal forming, important as these are, and no reference is made to the so-called high-energy forming methods or other forming techniques such as hydro-forming. I apologise for these omissions but emphasise the immense difficulties which are experienced when attempting to cover all these factors in a single text. It is, however, hoped that readers will be sufficiently stimulated by the subject matter of the present text to give further consideration to such matters and they are advised to refer to other literature specifically concerned with these topics. The references and bibliography have, therefore, been made as extensive as possible.

My sincere thanks and appreciation are offered to Professor W. Johnson formerly of the University of Manchester Institute of Science and Technology and now at the University of Cambridge. As a friend and teacher, Professor Johnson was responsible for introducing me to what I consider the most interesting of studies and occupations. I am also indebted to him for his stimulation by personal example in every respect.

The good influences of other past and present colleagues and students alike are also acknowledged, and thanks are due to Mrs. Susan Mahoney and Mrs. Ann Gray who typed parts of the manuscript. 